\title{
Über das Aufhören
}

\section{Eberhard Wolff}

Prof. Dr. rer. soc., Redaktor Kultur, Geschichte, Gesellschaft

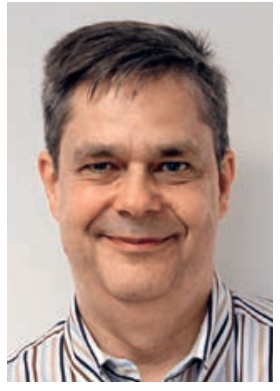

1 Interview mit Paul Simon in der NPR-Radiosendung "All Songs Considered" vom 5. September 2018. Online nachzuhören.

2 Seidenberg A. Heute ist der Tag: 5.4.2018. Schweiz Ärzteztg. 2018;99(16):509.

Tanner M, Christen P. "Keiner will meine Praxis». Schweiz Ärzteztg. 2017;98(47):1572-3.

4 Oertle D. Zukunft nach der Praxis. Schweiz Ärzteztg. 2018;99(15): 491-2.

Siehe das Beispiel des 88-jährigen Zürcher Pädiaters Willy Krauthammer in Hudec J. Paradox in der Pädiatrie (...). Neue Zürcher Zeitung, 9.10.2018.

6 Grete W. Ein Rezepturverbot für Ärztinnen und Ärzte im Ruhestand? Schweiz Ärzteztg. 2018;99(38):1295.

7 Thorwald J. Die Entlas sung. Das Ende des Chirurgen Ferdinand Sauerbruch. München Knaur; 1960.
Plötzlich hat ein Schalter in seinem Kopf «Klick» gemacht, und er wusste: Jetzt bin ich fertig mit meinem Job. Jetzt ist es Zeit aufzuhören - nach mehr als sechzig Jahren Praxis. Nein, ich spreche weder von einem verdienten Grundversorger noch von einem ebensolchen Herzchirurgen, sondern vom 77-jährigen Paul Simon und seinem Beruf, Lieder zu schreiben. Das hat Paul Simon kürzlich so in einem Radio-Interview erzählt [1]. Jetzt ist die Abschiedstournee auch vorbei. Seine TourWebsite ist leer.

Was bei ihm so einfach und überzeugend klingt, ist in Wirklichkeit eine überaus komplizierte und oft schmerzhafte Angelegenheit, auch und gerade im Medizinbereich. Das spiegelt sich in vielen SÄZ-Artikeln der letzten Zeit. Wann und wie wollen wir in unserem jeweiligen Beruf aufhören, wann können wir es, wann müssen wir und wann dürfen wir? In der Tat können wir die ganze Aufhörproblematik an den sogenannten Modalverben durchspielen, diesem grammatikalischen Phänomen unserer Sprache, das unsere Hauptverben mit Notwendigkeiten und Möglichkeiten präzisiert.

Einer der Vorteile der freiberuflichen Ärzte ist es bekanntlich, dass sie um die 65 erst einmal nicht aufhören müssen, wenn sie nicht aufhören wollen. Wenn sie dann zum Beispiel wegen ständig überfüllter Praxen aber doch aufhören wollen [2], kann es gut sein, dass sie nicht aufhören können oder im Sinne der Patientenversorgung nicht aufhören dürfen, weil sich keine geeigneten Praxisnachfolger(innen) finden [3].

Ganz anders bei den öffentlich angestellten Ärztinnen und Ärzten. Alle, die aufhören wollen, dürfen und können aufhören. Jederzeit, wenn sie es sich leisten können. Wenn sie aber nicht aufhören wollen, haben sie oft ein Problem, weil unser Arbeitssystem immer noch den Geist atmet, dass sie mit Eintritt des «ordentlichen Rentenalters» auch aufhören sollen und de facto meist sogar aufhören müssen. Trotz ein paar Ausnahmen neuerdings ist der archaische Gedanke, nach genau 65 (oder 64) Sonnenumkreisungen der Erdkugel seit der Geburt und nach Jahrzehnten aktiver Berufstätigkeit von einem Tag auf den anderen alles hinwerfen zu sollen, immer noch virulent. Von hundert auf null, im Prinzip zumindest. Eine immer grössere Zahl dieser Ärzte werden aber schon Jahre vor der Pensionierung von dem Gefühl beschlichen, so abrupt nicht aufhören $z u$ wollen, sondern irgendwie weiterzuarbeiten, denn die Vorstellung eines Lebens ohne Beruf verunsichert zunehmend [4]. Sie wechseln dann in die freie Praxis, teilweise bis ins hohe Alter [5]. Ich selber würde in sechs Jahren auch gerne noch weiter als Redaktor, Unidozent und installierter Wissenschaftler an Forschungsprojekten arbeiten.

Anfang Jahr hat der Kanton Zürich die sogenannten «Seniorenbewilligungen» abgeschafft, mit denen Ärzte im Ruhestand noch Angehörige und enge Freunde behandeln und Rezepte ausstellen dürfen [6]. Damit haben die selbständigen Ärzte auch einen Geschmack davon erhalten, was es heisst, als Ruheständler ganz aufhören zu müssen. Der Widerstand formiert sich. Und dann gibt es noch andere, die nicht aufhören können. Aus wirtschaftlichen Gründen zum Beispiel. In den USA arbeiten Uniprofs (ohne Pensionierungsgrenze) zum Teil weiter, um ihre Krankenversicherung nicht zu verlieren. Andere wollen die Eigenschaften ihres Berufs wie die Anerkennung nicht missen. Der Berliner Chirurg Ferdinand Sauerbruch (1875-1951, in Zürich 1910-1918) operierte offenbar noch, als seine Gehirnsklerose schon weit fortgeschritten war, und machte zunehmend Fehler. Ein reisserisches Skandalbuch machte dies 1960 öffentlich [7].

Mit dem Aufhören ist es also doch nicht immer so einfach, wie Paul Simon das leicht und luftig erzählt hat. Ozzy Osbourne, der auch schon siebzigjährige Säulenheilige des Heavy Metal, ist derzeit auf seiner Abschiedstour um die Welt unterwegs. Sie heisst augenzwinkernd "No More Tours 2", weil er seine erste Abschiedstournee bereits im Jahre 1992 gemacht hat. Ob er nun wirklich auf der letzten Tour ist, lässt er bewusst offen. Dabei ist nicht ganz klar, ob er das sagt, weil er nicht aufhören muss, will, darf oder kann. Und Paul Simon? Ich bin überzeugt, er macht weiter Musik, gibt Interviews, macht Projekte, solange er das noch kann. So wie ganz viele Ärzte und sonstige Berufsmenschen eben auch wollen.

Wer nicht gerade aufhören will, den sollte man heute auch noch arbeiten lassen, was er oder sie noch kann. Leonhard Cohen konnte seinen unendlich eindrucksvollen Abschiedssong «You Want It Darker» 2016 im multimorbiden Zustand nur noch zu Hause aufnehmen. Er wurde 19 Tage vor seinem Tod veröffentlicht. 